\title{
Prevalence of staphylococcal enterotoxins, toxin genes and genetic-relatedness of foodborne Staphylococcus aureus strains isolated in the Marmara Region of Turkey
}

\author{
Ali Aydin a,*, Mert Sudagidan ${ }^{\text {b }}$, Karlo Muratoglu a \\ a Department of Food Hygiene and Technology, Faculty of Veterinary Medicine, Istanbul University, Avcilar 34320, Istanbul, Turkey \\ ${ }^{\mathrm{b}}$ Biotechnology and Bioengineering Central Research Laboratory, Izmir Institute of Technology, Gulbahce Campus, Urla 35430, Izmir, Turkey
}

\section{A R T I C L E I N F O}

Article history:

Received 14 January 2011

Received in revised form 3 April 2011

Accepted 6 May 2011

Available online 14 May 2011

\section{Keywords:}

Staphylococcus aureus

Enterotoxin genes

Enterotoxins

PCR

ELISA

PFGE

\begin{abstract}
A B S T R A C T
Staphylococcus aureus is a major foodborne pathogen and it has the ability to produce a number of extracellular toxins. We analyzed 1070 food samples obtained from retail markets and dairy farms in the Marmara Region of Turkey for the presence of S. aureus. Out of 147 isolates, 92 (62.6\%) were enterotoxigenic. PCR was used to investigate the presence of staphylococcal enterotoxin genes (sea, seb, sec, sed, see, seg, seh, sei, sej, sek, sel, sem, sen, seo, sep, seq and seu), exfoliative toxin genes (eta and etb) and the toxic - shock syndrome toxin gene (tst). The PCR results showed that 53.3\% of the isolates contained staphylococcal enterotoxin-like (SEl) toxin genes (seg, seh, sei, sej, sek, sel, sem, sen, seo, sep, seq and seu) which were more frequent than classical enterotoxin genes (sea to see). Furthermore, seo, sei, sem, seg, seu and sec were found in $37.0,32.7,30.4,29.3,29.3$ and $27.2 \%$ of the isolates, respectively. The tst gene was detected and confirmed by DNA sequencing in 9 isolates. The presence of eta and $e t b$ were not found in the isolates. Enterotoxigenic capabilities of isolates with SEA-SEE were investigated by ELISA. Enterotoxigenic $S$. aureus isolates produced one to three enterotoxins, with the most frequently produced types being enterotoxin $\mathrm{A}$ and $\mathrm{C}$. There was a correlation of $72.1 \%$ between production of a specific toxin and the presence of the respective genes. PFGE analysis was used to identify genetic-relatedness of enterotoxigenic $S$. aureus isolates and the results revealed that 13 groups of isolates from different or the same origin that contained the same genes showed $100 \%$ homology with indistinguishable band patterns. The other enterotoxigenic isolates showed related band patterns with 72-86\% homology in sea-, 61-90\% homology in sec-, 80-96\% homology in seh-, and 69-96\% homology in sep-positive isolates. To our knowledge, this is the first study to examine enterotoxins and related gene contents of S. aureus food isolates in the Marmara Region of Turkey.
\end{abstract}

(c) 2011 Elsevier B.V. All rights reserved.

\section{Introduction}

Staphylococcus aureus is a pathogen associated with serious community and hospital-acquired diseases. Although the number of outbreaks reported annually has decreased in the last few decades, staphylococcal food poisoning is still reported as the third most prevalent cause of foodborne illness worldwide (Zhang et al., 1998). Illness is caused by enterotoxin-producing S. aureus (Cha et al., 2006; Sudagidan and Aydin, 2009; Wieneke et al., 1993). Raw meat (Pereira et al., 2009), meat products, including fermented products such as sucuk (Guven et al., 2010), raw milk (Rall et al., 2008), dairy products (Normanno et al., 2007) and ready-to-eat foods, including bakery products (Oh et al., 2007) are among the foods reported to be associated with $S$. aureus enterotoxin-induced food poisoning.

S. aureus produces more than 30 different extracellular byproducts (Rogolsky, 1979) and staphylococcal toxins can be catego-

\footnotetext{
* Corresponding author. Tel.: + 90 2124737070x17182; fax: +90 2124737241. E-mail address: aliaydin@istanbul.edu.tr (A. Aydin).
}

rized into groups: pyrogenic toxin superantigens (PTSAgs), exfoliative toxins, leukocidins and other toxins. The family of PTSAgs includes staphylococcal enterotoxins (SEs), SE-like (SEl) toxins and toxicshock syndrome toxin-1 (TSST-1) (Lina et al., 2004). Generally, five classical antigenic SE types (SEA to SEE) are recognized. Recently, the existence of new SEs including SEl toxins (i.e., SElG to SEIQ, SEIR and SEIU) has been reported (Bania et al., 2006; Jarraud et al., 2002; Nashev et al., 2007). However, their potential role in staphylococcal food poisoning has not yet been clarified (Lina et al., 2004). TSST-1 is associated with staphylococcal toxic-shock syndrome and is considered to be the cause of nearly all cases of menstrual toxic-shock syndrome and at least 50\% of nonmenstrual cases (Bergdoll and Schlievert, 1984). The presence of toxic-shock syndrome toxin gene (tst) in S. aureus isolated from foods has been reported (Cha et al., 2006). Moreover, clinical strains of $S$. aureus are known to produce immunologically distinct exfoliative toxin A and/or B (Bailey et al., 1980). The production of exfoliative toxin A by $S$. aureus isolated from foods and animals has been reported (Adesiyun et al., 1991; Hayakawa et al., 1998).

Various typing methods have been used to characterize S. aureus isolates. PCR has been used as a simple technique for detecting 
enterotoxigenic strains (Asperger and Zangerl, 2003). Although the PCR-based approach is specific, highly sensitive and rapid, it can only detect the presence of enterotoxigenic genes, not the production of the SE proteins (Boerema et al., 2006). Immunological methods are preferred for the detection of enterotoxins (Chiang et al., 2008). ELISA is the method of choice, because reagents are commercially available in polyvalent and monovalent formats for both toxin screening and serotype specific identification assays (Bennett, 2001). Numerous techniques [amplified fragment length polymorphism, multi locus sequence typing and pulsed-field gel electrophoresis (PFGE)] have been described for S. aureus genotyping (Melles et al., 2007), of which PFGE is the "gold standard" technique for determining geneticrelatedness, especially in outbreaks, due to its high discriminatory power (Weller, 2000).

The aim of this study was to determine the frequency of PTSAgs, including SE genes (sea, seb, sec, sed and see), SEl genes (seg, seh, sei, sej, sek, sel, sem, sen, seo, sep, seq and seu), tst and the coexistence of exfoliative genes (eta and etb) in S. aureus food isolates, to determine the ability of the isolates to produce staphylococcal enterotoxins A-E and to investigate the genetic-relatedness of enterotoxigenic S. aureus isolates by PFGE.

\section{Materials and methods}

\subsection{Sample collection and bacterial isolates}

During the period of July 2007 and December 2008, 1070 food samples were collected from supermarkets, conventional markets, bazaars and dairy farms in and near large cities, including Balikesir, Bursa, Canakkale, Edirne, Istanbul, Kirklareli and Tekirdag, in the Marmara Region of Turkey. These samples included 115 meats (beef, mutton, chicken and turkey meat), 15 meat products [Turkish type fermented sausage (sucuk)], salami and sausage), 303 raw milk, 452 dairy products (cheese, butter, yoghurt and cream), 141 bakery products [pasta, thin sheets of dough (yufka) and cake] and 44 readyto-eat foods. Raw milk samples were obtained from dairy farms located near these cities. Isolation of $S$. aureus from food samples was performed using EN ISO 6881-1 standard procedures described by the International Organization for Standardization (Anonymous, 1999). Procedures for identification of the isolates were previously described (Aydin et al., 2011).

\subsection{Detection of toxin genes}

Bacterial genomic DNA isolation was carried out as described previously (Sudagidan et al., 2008). The presence of staphylococcal enterotoxin genes sea, seb, sec and see (Johnson et al., 1991), sed (Jarraud et al., 2002; Johnson et al., 1991), seg, seh, sei, sej, sek, sel, sep and seq (Bania et al., 2006), sem, sen and seo (Jarraud et al., 2002) and seu (Nashev et al., 2007), and genes for exfoliative toxins (eta and etb) (Johnson et al., 1991) and toxic-shock syndrome toxin (tst) (Booth et al., 2001) was determined by either monoplex or multiplex PCR. The PCR products were resolved in $1.5 \%(\mathrm{w} / \mathrm{v})$ agarose gel electrophoresis in $1 \times$ TAE buffer $(0.04 \mathrm{M}$ Tris-acetate and $0.001 \mathrm{M}$ EDTA). PCR experiments were done twice for each isolate. Positive controls were S. aureus subsp. aureus NCTC (National Collection of Type Cultures) 10652 for sea, S. aureus subsp. aureus NCTC 10654 for seb, S. aureus subsp. aureus NCTC 10655 for sec and S. aureus subsp. aureus NCTC 10656 for sed. S. aureus N315, positive for tst, sem, sen, seo and seu, was kindly supplied by Dr. Teruyo Ito and Prof. Keiichi Hiramatsu from Juntendo University, Japan. S. aureus strains positive for seg, sei, sej, seh and seo genes were obtained from Department for Veterinary Public Health, Institute for Milk Hygiene, Milk Technology and Food Science, University of Veterinary Medicine, Wien, Austria.

\subsection{DNA sequencing of tst gene}

The DNA sequences of tst positive PCR products were determined using PCR primers described by Booth et al. (2001). The following conditions were used for cycle sequencing of tst genes: 1 min at $96{ }^{\circ} \mathrm{C}$, 30 cycles of $10 \mathrm{~s}$ at $96{ }^{\circ} \mathrm{C}, 5 \mathrm{~s}$ at $56^{\circ} \mathrm{C}$ (tst-forward and reverse) and

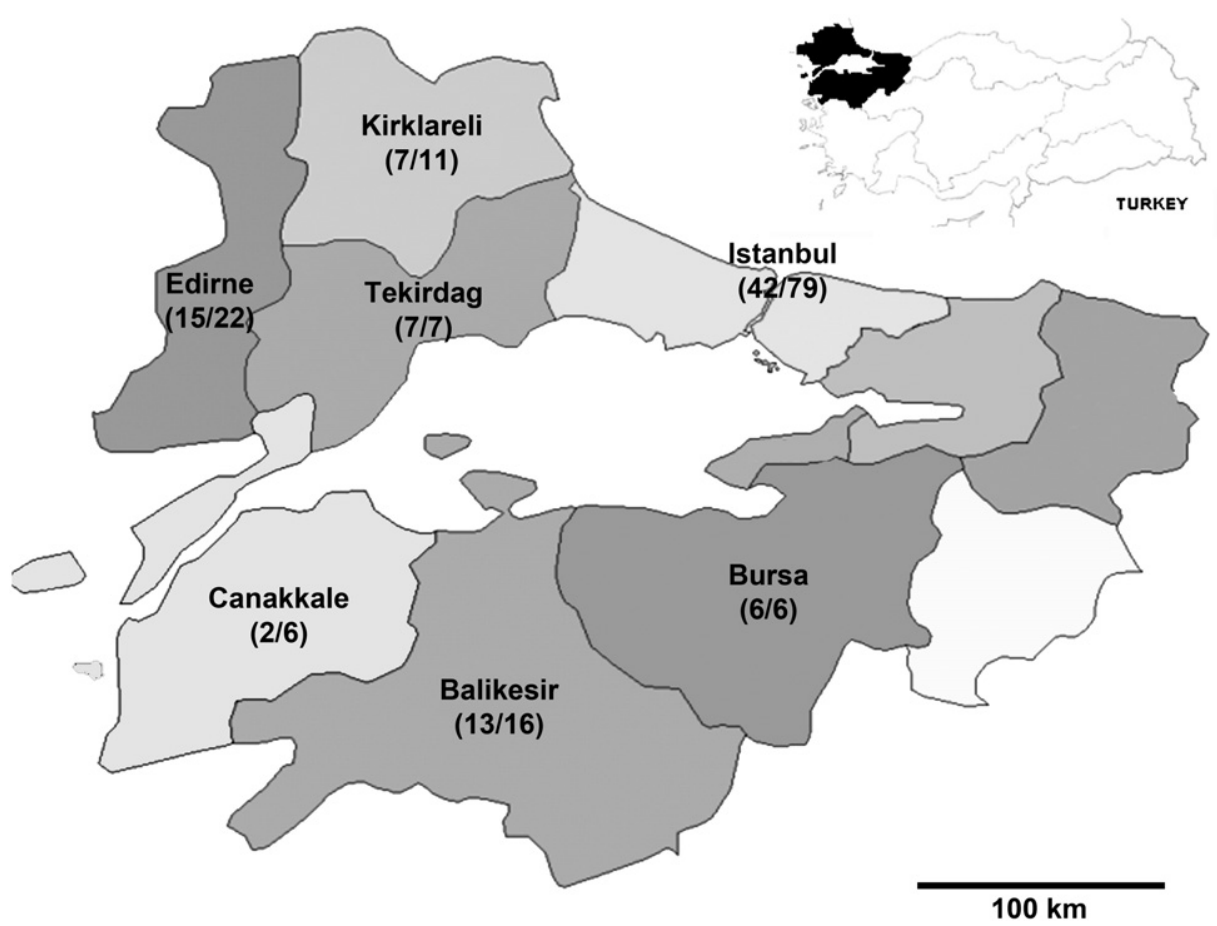

Fig. 1. Distribution of enterotoxigenic S. aureus isolates/total number of S. aureus isolates which were isolated from foods collected in the Marmara Region of Turkey. 
Table 1

The presence of enterotoxin genes in S. aureus isolates.

\begin{tabular}{|c|c|c|c|c|c|c|c|}
\hline Enterotoxin genes & $\begin{array}{l}\text { Meat } \\
(n=13)(\%)\end{array}$ & $\begin{array}{l}\text { Meat products } \\
(\%)(n=6)\end{array}$ & $\begin{array}{l}\text { Raw milk } \\
(\mathrm{n}=31)(\%)\end{array}$ & $\begin{array}{l}\text { Dairy products } \\
(\mathrm{n}=36)(\%)\end{array}$ & $\begin{array}{l}\text { Bakery products } \\
(\mathrm{n}=5)(\%)\end{array}$ & $\begin{array}{l}\text { Ready-to-eat food } \\
(\mathrm{n}=1)(\%)\end{array}$ & $\begin{array}{l}\text { Total } \\
(n=92)(\%)\end{array}$ \\
\hline sea & $1(7.7)$ & & $3(9.7)$ & $4(11.1)$ & & & $8(8.6)$ \\
\hline $\sec$ & & & $7(22.6)$ & $3(8.3)$ & & & $10(10.9)$ \\
\hline seh & $4(30.7)$ & & $1(3.2)$ & $3(8.3)$ & & & $8(8.6)$ \\
\hline sei & & & $1(3.2)$ & & & & $1(1.1)$ \\
\hline sel & $1(7.7)$ & & & & & & $1(1.1)$ \\
\hline sen & & & & $1(2.8)$ & & & $1(1.1)$ \\
\hline seo & & & $1(3.2)$ & $2(5.5)$ & & & $3(3.2)$ \\
\hline sep & $1(7.7)$ & & $4(13.0)$ & $6(16.6)$ & $1(20.0)$ & & $12(13.0)$ \\
\hline seu & & & & $1(2.8)$ & & & $1(1.1)$ \\
\hline sea, sec & & & $1(3.2)$ & $1(2.8)$ & & $1(100)$ & $3(3.2)$ \\
\hline sea, seh & & & $1(3.2)$ & & & & $1(1.1)$ \\
\hline sea, seq & & & & $1(2.8)$ & & & $1(1.1)$ \\
\hline seb, sec & & & & $1(2.8)$ & & & $1(1.1)$ \\
\hline seb, sep & $1(7.7)$ & & & $1(2.8)$ & & & $2(2.2)$ \\
\hline sec, seo & & & & & $1(20.0)$ & & $1(1.1)$ \\
\hline seg, sei & & & & $1(2.8)$ & & & $1(1.1)$ \\
\hline sel, sep & & & $2(6.5)$ & & & & $2(2.2)$ \\
\hline sem, seo & & & $1(3.2)$ & & & & $1(1.1)$ \\
\hline sec, sel, sep & & & & $1(2.8)$ & & & $1(1.1)$ \\
\hline seh, sek, seq & & & & & $1(20.0)$ & & $1(1.1)$ \\
\hline sem, seo, sep & & & $1(3.2)$ & & & & $1(1.1)$ \\
\hline sea, seh, sek, seq & & & $1(3.2)$ & & $1(20.0)$ & & $2(2.2)$ \\
\hline sec, sei, sel, sep & & & & $1(2.8)$ & & & $1(1.1)$ \\
\hline sea, seg, sei, seo, seu & & $1(16.7)$ & & & & & $1(1.1)$ \\
\hline seb, sek, sen, seo, seq & $1(7.7)$ & & & & & & $1(1.1)$ \\
\hline seg, sei, sem, sen, seo & & & & $1(2.8)$ & & & $1(1.1)$ \\
\hline seg, sei, sem, seo, seu & & $1(16.7)$ & & $4(11.1)$ & & & $5(5.4)$ \\
\hline seb, seg, sei, sem, seo, seu & & & & $1(2.8)$ & & & $1(1.1)$ \\
\hline seg, sei, sem, sen, seo, seu & $1(7.7)$ & & $3(9.7)$ & $2(5.5)$ & $1(20.0)$ & & $7(7.6)$ \\
\hline seg, sei, sem, seo, seq, seu & & & $1(3.2)$ & $1(2.8)$ & & & $2(2.2)$ \\
\hline sea, seg, sei, sem, sen, seo, seu & & $1(16.7)$ & & & & & $1(1.1)$ \\
\hline sec, seg, sei, sel, sem, seo, seu & $1(7.7)$ & & & & & & $1(1.1)$ \\
\hline sec, seg, sei, sem, sen, seo, seu & & & $1(3.2)$ & & & & $1(1.1)$ \\
\hline sec, seh, sei, sem, sen, seo, seu & & $1(16.7)$ & & & & & $1(1.1)$ \\
\hline seg, sei, sem, sen, seo, seq, seu & $1(7.7)$ & & & & & & $1(1.1)$ \\
\hline sec, seg, seh, sei, sem, sen, seo, seu & & $2(33.2)$ & & & & & $2(2.2)$ \\
\hline sec, seg, sei, sel, sem, sen, seo, seu & $1(7.7)$ & & $2(6.5)$ & & & & $3(3.2)$ \\
\hline
\end{tabular}

4 min at $60{ }^{\circ} \mathrm{C}$. The DNA sequencing was carried out using Applied Biosystems 3130xl Genetic Analyzer (Foster City, California, USA).

\subsection{Determination of enterotoxin production}

Enterotoxin production was determined by ELISA and enterotoxins were detected using a Ridascreen SET A, B, C, D, E assay kit (R-Biopharm AG, Germany). Briefly, the supernatant of $24 \mathrm{~h}$ cultures of $S$. aureus ( 9 $\log \mathrm{CFU} / \mathrm{ml}$ ) grown at $37^{\circ} \mathrm{C}$ in Brain Hearth Infusion Broth (BHI, Oxoid) was separated from cells by centrifugation at $4500 \times \mathrm{g}$ for 5 min at $4{ }^{\circ} \mathrm{C}$. The supernatant was passed through $0.20 \mu \mathrm{m}$ filter (Millipore) and $100 \mu \mathrm{l}$ of the filtrate were transferred to an ELISA plate. The solutions were mixed gently by rocking of the plate for $1 \mathrm{~h}$ at $23^{\circ} \mathrm{C}$ in the dark. To

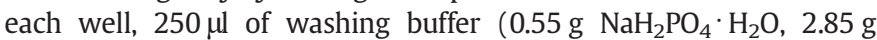
$\mathrm{Na}_{2} \mathrm{HPO}_{4} \cdot 2 \mathrm{H}_{2} \mathrm{O}, 8.7 \mathrm{~g} \mathrm{NaCl}$; pH 7.2) was added, followed by aspiration. This procedure was repeated three times. Subsequently, $100 \mu \mathrm{l}$ of peroxidase conjugated anti-SET antibodies were added to each well and incubated for $60 \mathrm{~min}$ at $23{ }^{\circ} \mathrm{C}$ in the dark. The liquid was then aspirated from the wells and the wells were rinsed three times with $250 \mu \mathrm{l}$ of wash buffer. Urea peroxide ( $50 \mu \mathrm{l})$ and tetramethyl-benzidine ( $50 \mu \mathrm{g}$ ) were added to each well, mixed thoroughly and incubated for $30 \mathrm{~min}$ at $23{ }^{\circ} \mathrm{C}$ in the dark. Stop reagent $\left(100 \mu \mathrm{l}\right.$ of $1 \mathrm{~N} \mathrm{H}_{2} \mathrm{SO}_{4}$ ) was added to each well and the absorbance was measured at $450 \mathrm{~nm}$ in an ELISA reader (ELX 800, Bio-tek Inst., Winooski, Vermont, USA) (Anonymous, 2003; Bennett, 2001).

\subsection{PFGE analysis}

Genetic-relatedness of 92 exterotoxigenic S. aureus food isolates was determined by PFGE analysis. Agarose plugs were prepared as described previously (Aydin et al., 2011; Sudagidan and Aydin, 2010). Bacterial DNA in plugs was digested with 30U Smal (Fermentas) for $18 \mathrm{~h}$, followed by applying to $1 \%(\mathrm{w} / \mathrm{v})$ pulsed-field certified agarose (BioRad) with a $5-40 \mathrm{~s}$ pulse time, $6 \mathrm{~V} / \mathrm{cm}, 120^{\circ}$ angle, at $14^{\circ} \mathrm{C}$ for $22 \mathrm{~h}$ using the CHEF-Mapper PFGE system (Bio-Rad). After electrophoresis, the gel was stained with ethidium bromide $(5 \mu \mathrm{g} / \mathrm{ml})$ and visualized with VersaDoc 4000MP image analyzer system (Bio-Rad). The obtained band patterns were analyzed using BIO-PROFIL Bio-1D++ software (Vilber Lourmat, France) at 13\% homology coefficient. The similarity between the isolates was determined automatically by specifying the formula of Nei and Li (1979). The clustering was performed by the unweighted pair group method with arithmetic mean (UPGMA) (Vilber Lourmat).

\section{Results and discussion}

\subsection{Prevalence of enterotoxin producing $S$. aureus in food samples}

Enterotoxin-producing S. aureus is one of the causative agents of foodborne intoxication and for this reason determination of its prevalence in foods is important with respect to assessing public health risks. In this study, 147 (13.8\%) S. aureus strains, which were isolated from 1070 food samples, were analyzed for toxigenic capabilities. Ninety-two strains (62.6\%) isolated from meat (13/13), meat products (6/6), raw milk (31/63), dairy products $(36 / 54)$, bakery products $(5 / 9)$ and ready-to-eat foods $(1 / 2)$ were enterotoxigenic. These strains were isolated mainly from samples collected in Istanbul $(n=42)$, Edirne $(n=15)$, Balikesir $(n=13)$, Tekirdag $(n=7)$, Kirklareli $(n=7)$, Bursa $(n=6)$ and Canakkale $(n=2)$ (Fig. 1). Similar results were reported by Guven et al. (2010). They isolated 138 S. aureus strains from 413 food samples collected in the 
central Anatolia region of Turkey and 83 (60.1\%) of the strains synthesized one or two enterotoxins. In Portugal, Pereira et al. (2009) observed that $101(68.2 \%)$ out of 148 S. aureus isolates from various foods were positive for the presence of genes coding for one or more enterotoxins. In another study, Normanno et al. (2007) found a similar prevalence in Italy, in which $59.8 \%$ of the S. aureus strains isolated from milk, dairy and meat products produced enterotoxins.

\subsection{Detection of genes encoding staphylococcal enterotoxins}

Studies on $S$. aureus isolated from foods have shown that the percentage of enterotoxigenic strains is considerably higher if the newly described SEl genes are considered together with genes encoding for the so-called classical enterotoxins (Bania et al., 2006; Le Loir et al., 2003). Enterotoxigenic S. aureus strains have different SE gene contents and they can harbor several of the genes. SE genes are located on plasmids (sed and sej), phages (sea, see and sep) and chromosomes (seb, sec, seg, seh, sei, sek, sel, sem, sen, seo and seq) (Kuroda et al., 2001). In this study, 17 SE and SEl genes were investigated. It was found that $53.3 \%$ of the isolates negative for sea to see carried SEl genes. This is in agreement with other studies showing higher percentages of SEl genes relative to classical SE genes (Bania et al., 2006; Nashev et al., 2007; Rosec and Gigaud, 2002).

In the present study, $8.6 \%$ of the enterotoxigenic isolates were found to encode only sea. In other studies, the sea was reported to be present in $15.4 \%$ (Cha et al., 2006) and $18.8 \%$ (Oh et al., 2007) of $S$. aureus strains isolated from foods. In our study, the highest percentage of single enterotoxigenic gene was sep (13\%) (Table 1). The sep gene is another potential superantigen and was detected in 19 enterotoxigenic $S$. aureus isolates (20.7\%), most commonly in dairy products $(\mathrm{n}=8)$ and raw milk $(\mathrm{n}=7)$. The seb gene was detected in 5 $S$. aureus isolates $(5.4 \%)$ isolated from meat and dairy products (Table 1). However, in one isolate (HE4D), seb was accompanied by the sek gene. Another study reported all seb-positive strains $(n=3)$ to be sek-negative (Bania et al., 2006). SEK has many of the biological activities associated with the SEs, including superantigenicity, pyrogenicity and the ability to enhance the lethality of endotoxin (Orwin et al., 2001). Enterotoxigenic S. aureus strains containing seq, known to occur jointly with sek (Bania et al., 2006). In this study, it was found that all sek-positive isolates (HE4D, S133A, YF62A and YF62B) were also positive for seq, whereas, 4 seq-positive isolates (PY38BY/1, PY92BY/2, S137AY and TE15A) did not contain sek. Furthermore, our results showed that none of the enterotoxigenic isolates contained sed, see and sej genes. Similar observations have been reported for the absence of see (Bania et al., 2006; Nashev et al., 2007; Pereira et al., 2009).

Kuroda et al. (2001) suggested a correlation among sec, sel and sep genes. We found that only two isolates, both from dairy products (PY178A and PY178B), contained sec, sel, and sep and only two isolates (HE25A and HE25B) contained sec and sel genes. Bania et al. (2006) reported that sec/sel-positive strains were sep-negative; thus, any relationship between these genes is not obvious. In this study, sec was detected in $27.2 \%$ of enterotoxigenic S. aureus isolates and among these isolates, $8 \%$ were found to carry sel. These results were in agreement with those reported by Bania et al. (2006) which demonstrated that $7.1 \%$ of $S$. aureus isolates contained sec and sel.

The coexistence of seg and sei genes on a common genetic element was presented by Jarraud et al. (2001) and, in our study, all segpositive isolates $(\mathrm{n}=28)$ were also positive for sei. Interestingly, 3 isolates (EU6A, PY178A and S226) containing sei did not contain seg. Similarly, MacLauchlin et al. (2000) detected 20 S. aureus isolates which were positive for seg and sei $(n=19)$ or for only sei $(n=1)$. Moreover, the SEU enterotoxin, encoded by seu, was homologous, but not identical to any known enterotoxins (Letertre et al., 2003) and the majority of our strains (29.4\%) contained seu gene and combinations with other enterotoxin genes (Table 1 ).
SElH has been shown to have emetic activity and is considered as a potential causative agent for food poisoning (Su and Wong, 1995). In the present study, seh was detected the only enterotoxin genes in $8(8.6 \%)$ of the isolates and totally in $15(16.3 \%)$ of the isolates seh and seh combinations with other enterotoxin genes were detected (Table 1). This prevalence was relatively lower than that (52\%) reported by Bania et al. (2006), but comparable to that found by Nashev et al. (2004), who reported a prevalence of $13.6 \%$ in clinical S. aureus isolates.

\subsection{Determination of enterotoxin production}

Enterotoxins that cause human illness are referred to as classical staphylococcal enterotoxins (SEA to SEE) (Cha et al., 2006). In approximately $5 \%$ of cases, classical enterotoxins are not detected and these cases have been attributed to the production of new enterotoxins (Kokan and Bergdoll, 1987; Su and Wong, 1995). The specificity of ELISA is very high and the detection of enterotoxins $\mathrm{A}, \mathrm{B}, \mathrm{C}, \mathrm{D}$ and $\mathrm{E}$ is highly sensitive (Bennett, 2001). In the present study, 46.7\% S. aureus isolates possessed the targeted classical SEs genes (sea, seb and sec). In addition, $72.1 \%$ of the enterotoxigenic $S$. aureus isolates produced enterotoxins SEASED, as detected by ELISA (Table 2). The most frequently encountered enterotoxins in foods are SEA (Oh et al., 2007; Tsen et al., 1998) and SEC (Soriano et al., 2002; Tamarapu et al., 2001). Our observations were in agreement with other studies. We found that 2, 8 and 10 of the isolates produced only SEB, SEA and SEC, respectively, however, in 11 of the

Table 2

Presence of the genes and the produced enterotoxins in S. aureus isolates.

\begin{tabular}{|c|c|c|c|c|c|c|c|c|}
\hline \multirow{2}{*}{$\begin{array}{l}\text { Isolates } \\
\left(\text { food }^{\mathrm{a}} \text {, } \text { origin }^{\mathrm{b}}\right)\end{array}$} & \multicolumn{4}{|c|}{ SEs detected by ELISA } & \multicolumn{4}{|c|}{ The genes detected by PCR } \\
\hline & SEA & SEB & SEC & SED & sea & $s e b$ & $\sec$ & Other SEl genes \\
\hline SE21A, M, Bu ${ }^{\mathrm{C}}$ & + & & & + & + & & & - \\
\hline HE4D, M, E & & + & & & & + & & sek, sen, seo, seq \\
\hline HE25A, M,E & & & + & & & & + & $\begin{array}{l}\text { seg, sei, sel, sem, sen, seo, } \\
\text { seu }\end{array}$ \\
\hline HE25B, M, E & & & + & & & & + & seg, sei, sel, sem, seo, seu \\
\hline TE2, M, I & & + & + & & & + & & sep \\
\hline EU6B, MP, I & & & + & & & & + & $\begin{array}{l}\text { seg, seh, sei, sem, sen, seo, } \\
\text { seu }\end{array}$ \\
\hline EU6C, MP, I & & & + & & & & + & $\begin{array}{l}\text { seg, seh, sei, sem, sen, seo, } \\
\text { seu }\end{array}$ \\
\hline EU7A, MP, I & + & & + & + & + & & & seg, sei, seo, seu \\
\hline EU7B, MP, I & + & & & & + & & & seg, sei, sem, sen, seo, seu \\
\hline S35A, RM, K & & & + & & & & + & seg, sei, sem, sen, seo, seu \\
\hline S133A, RM, T & + & & & & + & & & seh, sek, seq \\
\hline S158B, RM, T & & + & + & & & & + & $\begin{array}{l}\text { seg, sei, sel, sem, sen, seo, } \\
\text { seu }\end{array}$ \\
\hline S235, RM, I & + & & + & + & + & & + & - \\
\hline S255, RM, I & & & + & & & & + & - \\
\hline S269, RM, I & + & & & + & + & & & seh \\
\hline S272, RM, I & + & & + & + & + & & & - \\
\hline S273, RM, I & + & & & + & + & & & - \\
\hline PY6, DP, I & & + & & & & + & & sep \\
\hline PY92BY2, DP, I & + & & & & + & & & seq \\
\hline PY100C, DP, I & + & & & & + & & + & - \\
\hline PY104A, DP, I & + & & & & + & & & - \\
\hline PY104B, DP, I & + & & & & + & & & - \\
\hline PY178A, DP, K & & & + & & & & + & sei, sel, sep \\
\hline PY178B, DP, K & & & + & & & & + & sel, sep \\
\hline PY186A, DP, E & & + & + & & & + & & seg, sei, sem, seo, seu \\
\hline PY276, DP, B & + & & & + & + & & & - \\
\hline PY311B, DP, B & + & & & & + & & & - \\
\hline PY351A, DP, B & & & + & & & & + & - \\
\hline PY368A, DP, C & & & + & & & + & + & - \\
\hline YF62A, BP, B & + & & & & + & & & - \\
\hline YE15A, RTE, I & + & & & + & + & & + & - \\
\hline
\end{tabular}

a M: Meat; MP: Meat Products; RM: Raw Milk; DP: Dairy Products; BP: Bakery Products and RTE: Ready-To-Eat Food.

b B: Balikesir; Bu: Bursa; C: Canakkale; E: Edirne; I: Istanbul; K: Kirklareli; and T: Tekirdag.

c In 13 isolates, there was not a correlation between enterotoxin production and the related genes are shown in boldface type. 
isolates produced more than one enterotoxin (Table 2). There was $72.1 \%$ correlation between enterotoxin types and presence of the respective genes. Similarly, Pereira et al. (2009) demonstrated $80 \%$ correlation in S. aureus isolates using the VIDAS assay and PCR.

In 12 S. aureus isolates (EU6A, S35B, S182, S215, S217, S242, S258, S266, S267, P33A, PY376A and PY406B) positive for SE genes, the presence of enterotoxins were not detected by ELISA. The difference between PCR and ELISA results can also be explained by the low-level of staphylococcal enterotoxin production, i.e. below the threshold of immunoassay detection (Bystron et al., 2006). The concentration of toxin should be above $1 \mathrm{ng} / \mathrm{ml}$, which is the lowest detection limit of the test used in this study. Another explanation might be the incomplete expression of enterotoxigenic genes. Furthermore, SE production can be affected by environmental conditions such as temperature, pH and water activity (Nájera-Sánchez et al., 2003). The environment of enterotoxigenic $S$. aureus in food is important for both growth and production of enterotoxins.

According to the ELISA results, 8 of the enterotoxigenic isolates produced SED and 4 isolates (TE2, EU7A, S272 and PY186A) produced SEC; however, sed and sec were not detected in these isolates by PCR (Table 2). Five isolates were positive for SED, whereas 3 were positive for SEC and 3 were positive for SEC and SED. It is possible that these pairs of PCR primers (SEC1-SEC2 and SED1-SED2) had low specificity owing to small sequence differences between strains (Nájera-Sánchez et al., 2003). Moreover, one isolate (S158B) that produced SEB and SEC tested negative for the presence of seb, but positive for sec and SEl genes. According to the other reports, SEB and SEC share 62 to $64 \%$ amino acid identity (Bohach and Schlievert, 1987; Munson et al., 1998) and SEG is similar to SEB and SEC (Munson et al., 1998). In addition, 2 isolates (EU7A and PY186A) were positive SEC and SED and these isolates contained also SEl genes (seg, sei, sem, seo and seu). These differences might have resulted from the use of prepared polyclonal antibodies against each SE, which sometimes exhibit antigenic similarities among SEs and SEl toxins, thereby causing cross-reactions in the tests (Edwin et al., 1986). Because enterotoxins SEA-SEE and SEH also share nucleotide sequence identity ( $\geq 32 \%)$, it is possible that a new enterotoxin gene could also share nucleotide sequence identity with the characterized enterotoxins (Munson et al., 1998).

\subsection{Prevalence of tst gene}

TSST-1 has been detected in S. aureus isolates most commonly isolated from clinical samples with important clinical symptoms (Lappin and Ferguson, 2009), moreover, tst-positive isolates have been also isolated from various foods (Cha et al., 2006), poultry (Evans et al., 1983) and milk (Valle et al., 1991). In our study, 9.8\% of the enterotoxigenic S. aureus isolates were positive for tst. Moreover, PCR products of tst were also confirmed by DNA sequencing. This is in agreement with Cha et al. (2006), who reported a 12\% prevalence of tst in foodborne S. aureus isolates in Korea. Conversly, Tsen et al. (1998) found tst in $4.8 \%$ of clinical S. aureus isolates, but not in food
A
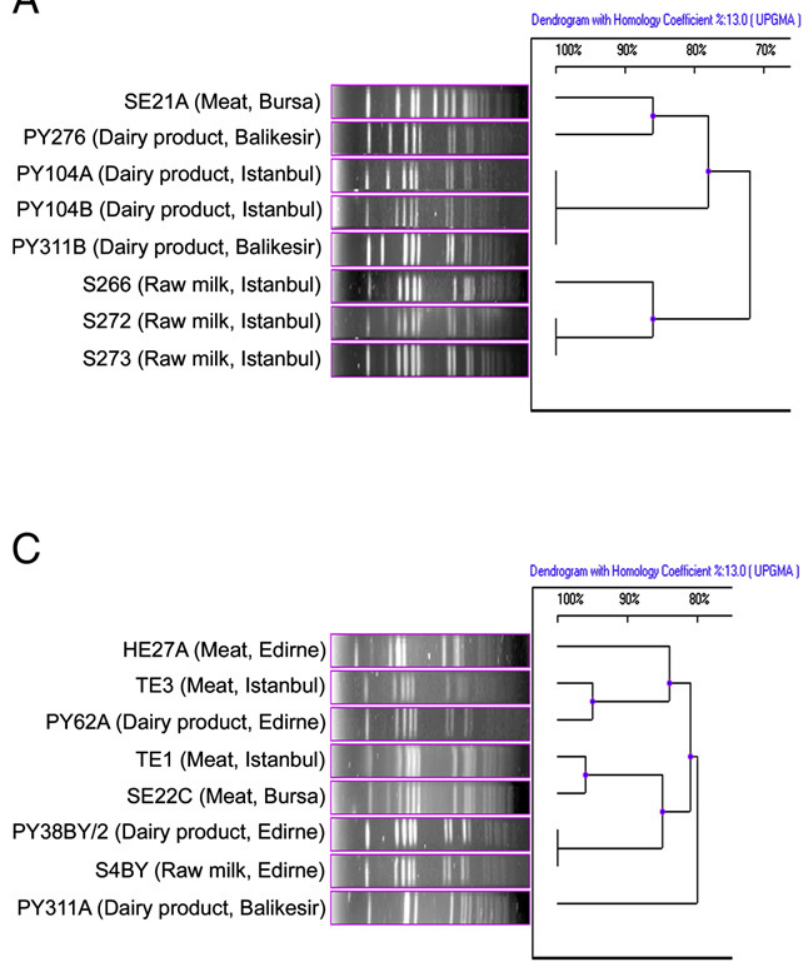

B
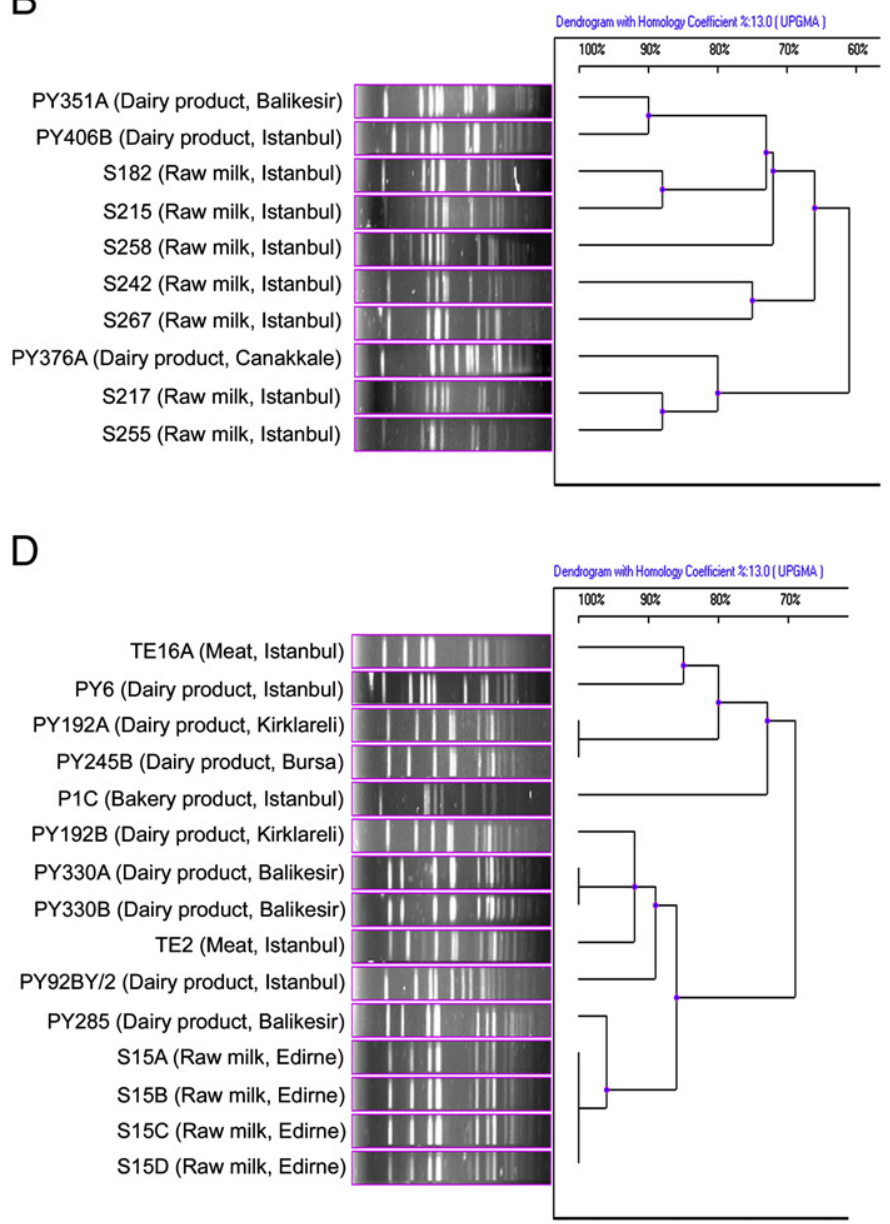


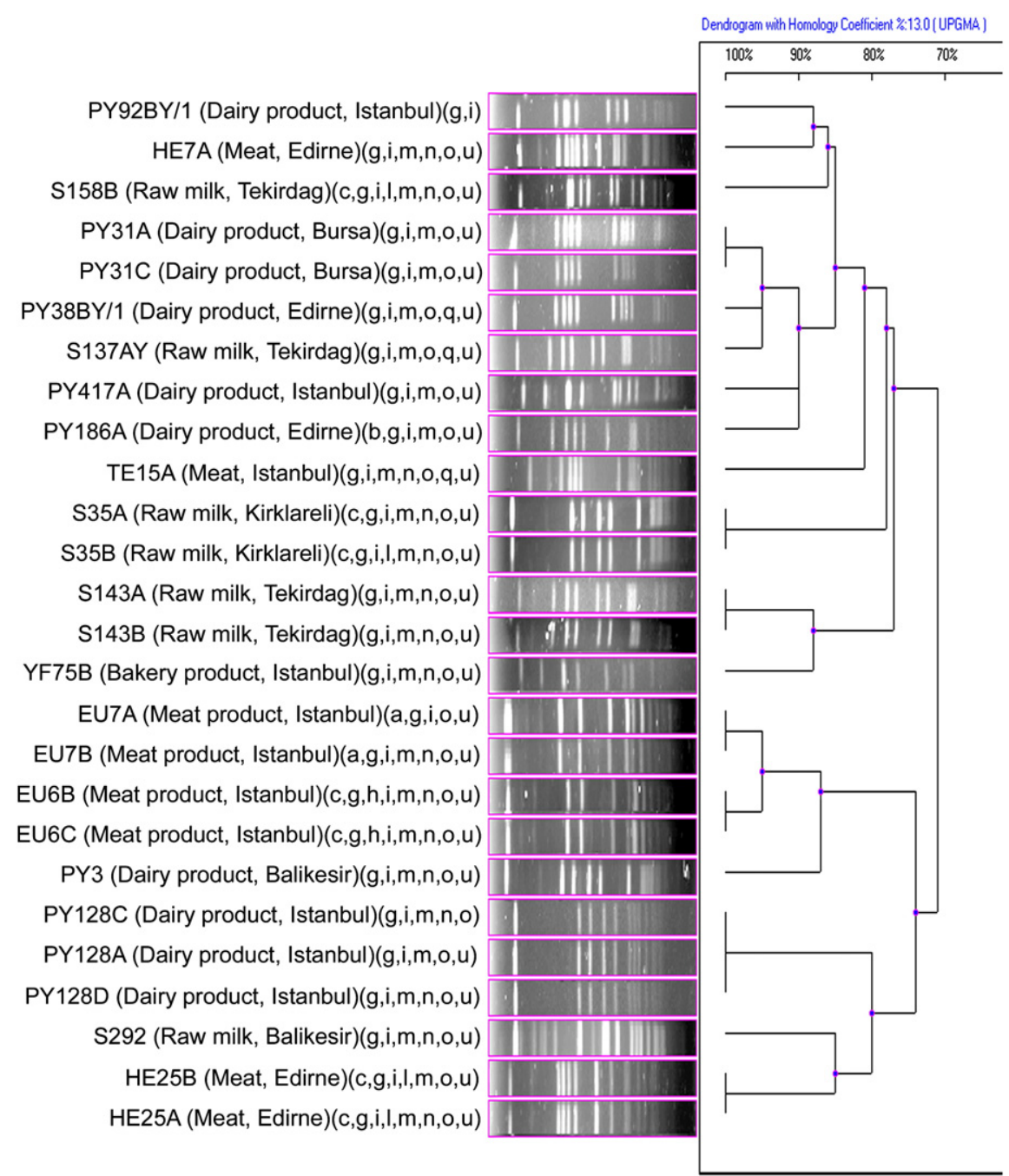

Fig. 3. Genetic-relatedness of 26 S. aureus isolates containing multi enterotoxin genes.

isolates. The probability of finding tst-positive foodborne $S$. aureus isolates would appear to be low (Tsen et al., 1998).

\subsection{Detection of eta and etb}

Genes encoding eta and etb-linked virulence factors are associated with bullous impetigo. In our study, none of the $S$. aureus isolates contained eta and etb genes. Similar to our results, Oh et al. (2007) and Karahan et al. (2009) could not find eta and etb in S. aureus isolated from ready-to-eat food and mastitic milk samples. On the other hand, Hayakawa et al. (1998) reported ETA in 1.2\% (2/162) and 0.6\% (1/166) of $S$. aureus isolates from mastitic cows' milk and bulk milk, respectively. Interestingly, these eta-positive $S$. aureus isolates did not cause general exfoliation of the epidermis accompanied by the socalled Nikolsky sign when inoculated into neonatal mice.

\subsection{PFGE analysis of the enterotoxigenic strains}

In the PFGE analysis, digestion of enterotoxigenic $S$. aureus strains' DNA with SmaI resulted in 9-15 fragments and the band patterns were grouped and compared to each other. Fig. 2 shows the geneticrelatedness of $8 \mathrm{sea}$-, $10 \mathrm{sec}$-, $8 \mathrm{seh}$ - and $15 \mathrm{sep}$-positive isolates. Three S. aureus isolates (PY104A, PY104B and PY311B) isolated from dairy products obtained in Istanbul and Balikesir and two isolates (S272 and S273) from raw milk samples obtained in Istanbul showed $100 \%$ homology with indistinguishable band patterns. The other sea- positive isolates displayed $72-86 \%$ homology (Fig. 2A). However, the band patterns of ten sec-positive isolates showed variations (61$90 \%$ homology) (Fig. 2B). There was no unique clonal type among secpositive isolates. S. aureus containing the sec were isolated mainly from raw milk samples collected in Istanbul. When the band patterns of seh-positive isolates were examined, only 2 isolates (PY38BY/2 and S4BY) from dairy products collected in Istanbul and raw milk in Edirne showed $100 \%$ homology. Other seh-containing isolates from meat and

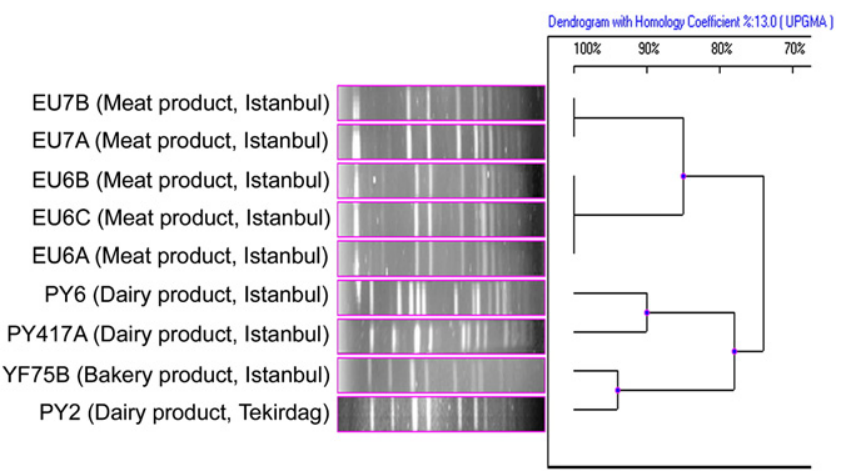

Fig. 4. Genetic-relatedness of tst-positive S. aureus isolates. 
dairy product samples were closely related (80-96\% homology) (Fig. 2C). Fifteen sep-positive isolates displayed 69-100\% homology. Four isolates (S15A, S15B, S15C and S15D) from raw milk samples collected in Edirne and 2 isolates (PY330A and PY330B) from dairy products in Balikesir had the same band patterns. Interestingly, 2 isolates (PY192A and PY245B) from dairy products collected in different cities (Kirklareli and Bursa) showed 100\% homology (Fig. 2D). S. aureus isolates obtained from dairy products and raw milk samples frequently contained the sep-gene.

The genetic-relatedness of $S$. aureus isolates containing multi enterotoxin genes is shown in Fig. 3. Aside from the identical strains, $11 \mathrm{~S}$. aureus isolates displayed 71-95\% homology. Seven groups of the isolates showed 100\% homology. In these groups, 3 isolates (PY128A, PY128C and PY128D) and 6 groups of isolates (EU6B and EU6C, EU7A and EU7B, HE25A and HE25B, PY31A and PY31C, S35A and S35B and S143A and S143B) displayed $100 \%$ homology. These isolates were obtained from meat products, dairy products and raw milk samples. Isolates containing the same genes were closely related with more than $80 \%$ homology (Fig. 3).

The presence of tst in our S. aureus isolates was low. The genetic relatedness of 9 tst-positive isolates is shown in Fig. 4. The dendrogram of tst-positive isolates is composed of two main groups with 74\% homology. One group is composed of 3 isolates (EU6A, EU6B and EU6C) and 2 isolates (EU7A and EU7B) all of which isolated from meat products and showed 100\% homology. Another group contains 4 isolates (Fig. 4). S. aureus YF75B (from a bakery product) and PY2 (from a dairy product) showed $94 \%$ homology and they were isolated from samples collected in different cities. Moreover, 2 S. aureus isolates, which were isolated from dairy products in Istanbul, showed $90 \%$ homology. All tst-positive S. aureus isolates were closely related, with more than $74 \%$ homology.

\section{Conclusions}

The recent discovery and characterization of new SEs resulted in an increased frequency of potentially enterotoxigenic $S$. aureus isolates from foods, suggesting that the prevalence pathogenic $S$. aureus may be higher than the previously recognized. The high prevalence of newly discovered enterotoxin genes, including those encoding emetic toxins, is evident in foodborne isolates. In light of these observations, additional work is needed to better understanding the role of $S$. aureus in food poisoning and also to monitor the presence of these genes in foodborne isolates. The results demonstrated the high prevalence of newly discovered genes in foodborne $S$. aureus, especially in the isolates positive for classical enterotoxins, thus contributing to the prevalence of isolates potentially capable of causing food poisoning. The distribution of other genes suggests the possibility of the presence of yet unknown genetic elements encoding SEls. PFGE analysis showed a high genetic diversity among strains, indicating that contamination of various food products with S. aureus could originate from numerous sources, preprocessing environments, processing areas and the market place.

\section{Acknowledgements}

The authors thank Prof. Dr. Larry Beuchat (University of Georgia, Center for Food Safety) for critical reading of the manuscript. Furthermore, the authors thank Biotechnology and Bioengineering Central Research Laboratory (Izmir Institute of Technology) and Res. Assist. Funda Yilmaz (Istanbul University, Department of Food Hygiene and Technology). This work was supported by The Scientific and Technological Research Council of Turkey (TUBITAK) (Project No: 107T266) and by the Research Fund of Istanbul University, Project No: UDP-3645/13042009. A part of this study was presented in the 3rd National Veterinary Food Hygiene Congress (May 14-16, 2009) in Bursa, Turkey.

\section{References}

Adesiyun, A.A., Lenz, W., Schaal, K.P., 1991. Exfoliative toxin production by Staphylococcus aureus strains isolated from animals and human beings in Nigeria. Microbiologica 14, 357-362.

Anonymous, 1999. International Organization for Standardization. EN ISO 6881-1 Microbiology of food and animal feeding stuffs: horizontal method for the enumeration of coagulase positive staphylococci (Staphylococcus aureus and other species). Part 1: technique using Baird Parker agar medium. ISO Geneva, Switzerland.

Anonymous, 2003. Enzyme immunoassay for the detection of Staphylococcus aureus enterotoxins. RIDASCREEN ${ }^{\circledR}$ SET A, B, C, D and E Art. No.: R1401. R-Biopharm AG, Darmstadt, Germany.

Asperger, H., Zangerl, P., 2003. Staphylococcus aureus. In: Roginski, H., Fuquay, J.W., Fox, P.F. (Eds.), Encyclopedia of Dairy Sciences. Academic Press and Elsevier Science, Amsterdam, pp. 2563-2569.

Aydin, A., Muratoglu, K., Sudagidan, M., Bostan, K., Okuklu, B., Harsa, S., 2011. Prevalance and antibiotic resistance of foodborne Staphylococcus aureus isolates in Turkey. Foodborne Pathogens and Disease 8, 63-69.

Bailey, C.J., de Azavedo, J., Arbuthnott, J.P., 1980. A comparative study of two serotypes of epidermolytic toxin from Staphylococcus aureus. Biochimica et Biophysica Acta 624, 111-120.

Bania, J., Dabrowska, A., Bystron, J., Korzekwa, K., Chrzanowska, J., Molenda, J., 2006. Distribution of newly described enterotoxin-like genes in Staphylococcus aureus from food. International Journal of Food Microbiology 108, 36-41.

Bennett, R.W., 2001. Staphylococcal enterotoxins. Micro-slide double diffusion and ELISA based methods. FDA/Bacteriological Analytical Manual. Chapter 13A. Available online: http://www.fda.gov/Food/ScienceResearch/LaboratoryMethods/ BacteriologicalAnalyticalManualBAM/UCM073674\#authors.

Bergdoll, M.S., Schlievert, P.M., 1984. Toxin shock syndrome toxin. Lancet 324, 691

Boerema, J.A., Clemens, R., Brightwell, G. 2006. Evaluation of molecular methods to determine enterotoxigenic status and molecular genotype of bovine, ovine, human and food isolates of Staphylococcus aureus. International Journal of Food Microbiology 107, 192-201.

Bohach, G.A., Schlievert, P.M., 1987. Nucleotide sequence of the staphylococcal enterotoxin C1 gene and relatedness to other pyrogenic toxins. Molecular and General Genetics 209, 15-20.

Booth, M.C., Pence, L.M., Mahasreshti, P., Callegan, M.C., Gilmore, M.S., 2001. Clonal associations among Staphylococcus aureus isolates from various sites of infection. Infection and Immunity 69, 345-352.

Bystron, J., Bania, J., Zarczynska, A., Korzekwa, K., Molenda, J., Kosek-Paszkowska, K., 2006. Detection of enterotoxigenic Staphylococcus aures strains using a commercial ELISA and multiplex-PCR. Bulletin of Veterinary Institute Pulawy 50, 329-333.

Cha, J.O., Lee, J.K., Jung, Y.H., Yoo, J.I., Park, Y.K., Kim, B.S., Lee, Y.S., 2006. Molecular analysis of Staphylococcus aureus isolates associated with staphylococcal food poisoning in South Korea. Journal of Applied Microbiology 101, 864-871.

Chiang, Y.C., Liao, W.W., Fan, C.M., Pai, W.Y., Chiou, C.S., Tsen, H.Y., 2008. PCR detection of Staphylococcal enterotoxins (SEs) N, O, P, Q, R, U, and survey of SE types in Staphylococcus aureus isolates from food-poisoning cases in Taiwan. International Journal of Food Microbiology 121, 66-73.

Edwin, C., Tatini, S.R., Maheswaran, S.K., 1986. Specificity and cross-reactivity of staphylococcal enterotoxin A monoclonal antibodies with enterotoxins B, C, D and E. Applied and Environmental Microbiology 52, 1253-1257.

Evans, J.B., Ananaba, G.A., Pate, C.A., Bergdoll, M.S., 1983. Enterotoxin production by atypical Staphylococcus aureus from poultry. Journal of Applied Bacteriology 54, 257-261.

Guven, K., Mutlu, B.M., Gulbandilar, A., Cakir, P., 2010. Occurence and characterization of Staphylococcus aureus isolated from meat and dairy products consumed in Turkey. Journal of Food Safety 30, 196-212.

Hayakawa, Y., Hayashi, M., Shimano, T., Komae, H., Takeuchi, K., Endou, M., Igarashi, H., Hashimoto, N., Takeuchi, S., 1998. Production of exfoliative toxin A by Staphylococcus aureus isolated from mastitic cow's milk and farm bulk milk. The Journal of Veterinary Medical Science 60, 1281-1283.

Jarraud, S., Peyrat, M.A., Lim, A., Tristan, A., Bes, M., Mougel, C., Etienne, J., Vandenesch, F., Bonneville, M., Lina, G., 2001. egc, A highly prevalent operon prevalent operon of enterotoxin gene, forms a putative nursery of superantigens in Staphylococcus aureus. The Journal of Immunology 166, 669-677.

Jarraud, S., Mougel, C., Thioulouse, J., Lina, G., Meugnier, H., Forey, F., Nesme, X., Etienne, J., Vandenesch, F., 2002. Relationships between Staphylococcus aureus genetic background, virulence factors, agr groups (alleles) and human disease. Infection and Immunity 70, 631-641.

Johnson, W.M., Tyler, S.D., Ewan, E.P., Ashton, F.E., Pollard, D.R., Rozee, K.R., 1991. Detection of genes for enterotoxins, exfoliative toxins and toxic shock syndrome toxin 1 in Staphylococcus aureus by the polymerase chain reaction. Journal of Clinical Microbiology 29, 426-430.

Karahan, M., Acik, M.N., Cetinkaya, B., 2009. Investigation of toxin genes by polymerase chain reaction in Staphylococcus aureus strains isolated from bovine mastitis in Turkey. Foodborne Pathogens and Disease 6, 1029-1035.

Kokan, N.P., Bergdoll, M.S., 1987. Detection of low-enterotoxin producing Staphylococcus aureus strains. Applied and Environmental Microbiology 53, 2675-2676.

Kuroda, M., Ohta, T., Uchiyama, I., Baba, T., Yuzawa, H., Kobayashi, I., Cui, L., Oguchi, A., Aoki, K., Nagai, Y., Lian, J., Ito, T., Kanamori, M., Matsumaru, H., Maruyama, A., Murakami, H., Hosoyama, A., Mizutani-Ui, Y., Takahashi, N.K., Sawano, T., Inoue, R., Kaito, C., Sekimizu, K., Hirakawa, H., Kuhara, S., Goto, S., Yabuzaki, J., Kanehisa, M., Yamashita, A., Oshima, K., Furuya, K., Yoshino, C., Shiba, T., Hattori, M., Ogasawara, N., Hayashi, H., Hiramatsu, K., 2001. Whole genome sequencing of meticillinresistant Staphylococcus aureus. Lancet 357, 1225-1240. 
Lappin, E., Ferguson, A.J., 2009. Gram-positive toxic shock syndromes. The Lancet Infectious Diseases 9, 281-290.

Le Loir, Y., Baron, F., Gautier, M., 2003. Staphylococcus aureus and food poisoning. Genetics and Molecular Research 31, 63-76.

Letertre, C., Perelle, S., Dilasser, F., Fach, P., 2003. Identification of a new putative enterotoxin SEU encoded by the egc cluster of Staphylococcus aureus. Journal of Applied Microbiology 95, 38-43.

Lina, G., Bohach, G.A., Nair, S.P., Hiramatsu, K., Jouvin-Marche, E., Mariuzza, R., 2004 Standard nomenclature for superantigens expressed by Staphylococcus. The Journal of Infectious Disease 189, 2334-2336.

MacLauchlin, J., Narayanan, G.L., Mithani, V., O'Neill, G., 2000. The detection of enterotoxins and toxic shock syndrome toxin genes in Staphylococcus aureus by polymerase chain reaction. Journal of Food Protection 63, 479-488.

Melles, D.C., Van Leeuwen, W.B., Snijders, S.V., Horst-Kreft, D., Peeters, J.K., Verbrugh, H.A., Van Belkum, A., 2007. Comparison of multilocus sequence typing (MLST), pulsedfield gel electrophoresis (PFGE), and amplified fragment length polymorphism (AFLP) for genetic typing of Staphylococcus aureus. Journal of Microbiological Methods 69, 371-375.

Munson, S.H., Tremaine, M.T., Betley, M.J., Welch, R.A., 1998. Identification and characterization of staphylococcal enterotoxin types $\mathrm{G}$ and I from Staphylococcus aureus. Infection and Immunity 66, 3337-3348.

Nájera-Sánchez, G., Maldonado-Rodríguez, R., Olvera, P.R., de la Garza, L.M., 2003. Development of two multiplex polymerase chain reactions for the detection of enterotoxigenic strains of Staphylococcus aureus isolated from foods. Journal of Food Protection 66, 1055-1062.

Nashev, D., Toshkova, K., Salasia, S.I.O., Hassan, A.A., Lämmler, C., Zschöck, M., 2004 Distribution of virulence genes of Staphylococcus aureus isolated from stable nasal carriers. FEMS Microbiology Letters 233, 45-52.

Nashev, D., Toshkova, K., Bizeva, L., Akineden, Ö., Lämmler, C., Zschöck, M., 2007. Distribution of enterotoxin genes among carriage- and infection-associated isolates of Staphylococcus aureus. Letters in Applied Microbiology 45, 681-685.

Nei, M., Li, W.-H., 1979. Mathematical model for studying genetic variation in terms of restriction endonucleases. Proceedings of the National Academy of Sciences USA 76, 5269-5273.

Normanno, G., La Salandra, G., Dambrosio, A., Quaglia, N.C., Corrente, M., Parisi, A., Santagada, G., Firinu, A., Crisetti, E., Celano, G.V., 2007. Occurrence, characterization and antimicrobial resistance of enterotoxigenic Staphylococcus aureus isolated from meat and dairy products. International Journal of Food Microbiology 115, 290-296.

Oh, S.K., Lee, N., Cho, Y.S., Shin, D.B., Choi, S.Y., Koo, M., 2007. Occurrence of toxigenic Staphylococcus aureus in ready-to-eat food in Korea. Journal of Food Protection 70, 1153-1158.

Orwin, P.M., Leung, D.Y., Donahue, H.L., Novick, R.P., Schlievert, P.M., 2001. Biochemical and biological properties of Staphylococcal enterotoxin K. Infection and Immunity 69, 360-366.
Pereira, V., Lopes, C., Castro, A., Silva, J., Gibbs, P., Teixeira, P., 2009. Characterization for enterotoxin production, virulence factors, and antibiotic susceptibility of Staphylococcus aureus isolates from various foods in Portugal. Food Microbiology 26 $278-282$.

Rall, V.L.M., Vieira, F.P., Rall, R., Vieitis, R.L., Fernandes Jr., A., Candeias, J.M.G., Cardoso, K.F.G., Araújo Jr., J.P., 2008. PCR detection of staphylococcal enterotoxin genes in Staphylococcus aureus strains isolated from raw and pasteurized milk. Veterinary Microbiology 132, 408-413.

Rogolsky, M., 1979. Nonenteric toxins of Staphylococcus aureus. Microbiological Reviews 43, 320-360.

Rosec, J.P., Gigaud, O., 2002. Staphylococcal enterotoxin genes of classical and new types detected by PCR in France. International Journal of Food Microbiology 77, 61-70.

Soriano, J.M., Font, G., Rico, H., Molto, J.C., Manes, J., 2002. Incidence of enterotoxigenic Staphylococci and their toxins in food. Journal of Food Protection 65, 857-860.

Su, Y.C., Wong, A.C., 1995. Identification and purification of a new staphylococcal enterotoxin H. Applied and Environmental Microbiology 61, 1438-1443.

Sudagidan, M., Aydin, A., 2009. Screening virulence properties of staphylococci isolated from meat and meat products. Wiener Tierärztliche Monatsschrift 96, 128-134

Sudagidan, M., Aydin, A., 2010. Virulence properties of methicillin-susceptible Staphylococcus aureus food isolates encoding Panton-Valentine Leukocidin gene. International Journal of Food Microbiology 138, 287-291.

Sudagidan, M., Çavuşoğlu, C., Bacakoğlu, F., 2008. Investigation of the virulence genes in methicillin-resistant Staphylococcus aureus strains isolated from biomaterial surfaces. Mikrobiyoloji Bülteni 42, 29-39.

Tamarapu, S., Mckillip, J.L., Drake, M., 2001. Development of a multiplex polymerase chain reaction assay for detection and differentiation of Staphylococcus aureus in dairy products. Journal of Food Protection 64, 664-668.

Tsen, H.Y., Yu, G.K., Wang, K.C., Wang, S.J., Chang, M.Y., Lin, L.Y., 1998. Comparison of the enterotoxigenic types, toxic shock syndrome toxin 1 (TSST-1) strains and antibiotic susceptibilities for enterotoxigenic Staphylococcus aureus strains isolated from food and clinical samples. Food Microbiology 15, 33-41.

Valle, J., Vadillo, S., Piriz, S., Gomez-Lucia, E., 1991. Toxic shock syndrome toxin 1 (TSST-1) production by staphylococci isolated from goats and presence of specific antibodies to TSST-1 in serum and milk. Applied and Environmental Microbiology 57, 889-891.

Weller, T.M.A., 2000. Methicillin-resistant Staphylococcus aureus typing methods: which should be the international standard? Journal of Hospital Infection 44, $160-172$.

Wieneke, A.A., Roberts, D., Gilbert, R.J., 1993. Staphylococcal food poisoning in the United Kingdom, 1969-1990. Epidemiology and Infection 110, 519-531.

Zhang, S., Iandolo, J., Stewart, C., 1998. The enterotoxin D plasmid of Staphylococcus aureus encodes a second enterotoxin determinant (sej). FEMS Microbiology Letters $168,227-233$. 